\title{
Reformas en la Universidad de Salamanca de los primeros Borbones (1700-1759) *
}

JUAN LUIS POLO RODRIGUEZ

La Universidad de Salamanca de las seis primeras décadas del siglo XVIII experimenta un conjunto de iniciativas de diferente naturaleza, y por ello mismo de difícil caracterización, pero que responden a una idéntica finalidad que les da coherencia: el cambio, la regeneración del Estudio salmantino, la recuperación del esplendor perdido. El Rey y su Consejo Real, la figura del cancelario de la Universidad, los claustrales y determinados catedráticos constituyen los diversos focos de irradiación de una serie de medidas y propuestas que tienen por objeto la transformación de la institución universitaria salmantina, pero que adolecen de la coordinación y homogeneidad necesarias para que pudiesen cristalizar. En efecto, las manifestaciones reformistas son variadas, en ocasiones contradictorias; los elementos precursores de la reforma en una determinada orientación, pueden impedir otros planteamientos revisionistas, las iniciativas carecen de continuidad. Resulta inútil encontrar un proyecto de cambio unitario y progresivo, no existe; sin embargo, el ambiente inconformista que se respira intra y extramuros permite caracterizar un periodo de la historia de la Universidad de Salamanca y comprender mejor el siglo XVIII ilustrado en el ámbito universitario salmantino $y$, dada su entidad, en el contexto universitario español.

El presente trabajo presenta una visión sintética de la reforma universitaria salmantina en el reinado de los primeros Borbones; reforma entendida en sentido amplio, englobando voluntades con intereses no coin-

* El presente artículo se encuadra en el Proyecto de Investigación PS90-0252 de la Dirección General de Investigación Científica y Técnica, titulado «Legislación y poderes en las Universidades Hispanas. El modelo de Salamanca (siglos XV-XIX)". 
cidentes, que nos presentan la institución al desnudo, con sus carencias estructurales ${ }^{1}$.

\section{UNA REFORMA ECONÓMICA NECESITADA Y NO QUERIDA}

Un primer bloque de medidas reformistas pretenden remover directamente los cimientos universitarios y alterar las estructuras universitarias en una doble faceta: hacienda universitaria y provisión de cátedras. Consideraremos en primer lugar la reforma económica generada en el seno mismo de la institución universitaria.

A pesar de que la Universidad de Salamanca disfrutaba de sólidas bases financieras, consistentes en las tercias que generaba el obispado salmantino y territorio comprendido en la Abadía de Medina del Campo, y un importante patrimonio, que permitían la obtención de abundantes rentas; sin embargo, adolecía de un presupuesto ajustado y susceptible a la coyuntura exterior, que impedía el desarrollo económico de la institución.

Tal situación obedecía a un reparto desproporcionado de las rentas del Estudio que favorecía a los catedráticos de propiedad y que se había ido gestando con el tiempo ${ }^{2}$. Estos pagos privilegiados ahogaban las posibilidades de ahorro e inversión que tenía el establecimiento docente,

\footnotetext{
1 Las fuentes documentales que sirven de base a la investigación son los Libros de Claustros correspondientes a los años que estamos considerando: cursos 1700/01-1758/59, A.U.S. (en adelante Archivo Universitario de Salamanca) 169-227. En las actas de las sesiones claustrales, puestas a limpio, se copian las cédulas y provisiones reales más significativas; y en los libros se insertan los proyectos de reforma generados por los graduados universitarios.

Los originales, copias y borradores de tales infomaciones se localizan en los siguientes cuerpos documentales: Documentos Reales. Provisiones, cédulas y demás documentos reales referentes a la Universidad de Salamanca: A.U.S. 2.875-2.878. Correspondencia del Real y Supremo Consejo de Castilla con la Universidad de Salamanca sobre asuntos universitarios, A.U.S. 2.887, fs. 73-342. Documentos varios de informes y correspondencia sobre asuntos universitarios tocantes a la Universidad de Salamanca (2 legs.): A.U.S. 2.030, secciones 2, 5, 10, 14, 15, 17-19; A.U.S. 2.031, secciones 7, 10-14, 16, 23 y 24. Reglamentación y planes de estudios de la Universidad de Salamanca y sus facultades. Reales provisiones, cédulas y órdenes de reforma de enseñanza (1 leg.), A.U.S. 2.032, secciones 5-7, 14, 15, 17, 19 y 35 . Estatutos manuscritos de la Universidad de Salamanca, A.U.S. 2.885, fs. 13-22v del último cuadernillo.

2 La docencia del Estudio salmantino se estructuraba en 25 cátedras de propiedad que cobraban en florines, 2 cátedras de propiedad con asignados fijos y 34 cátedras cursatorias, partidos y primarias con sueldos también fijos. Los 25 catedráticos de propiedad florinistas de la Universidad, absorbían el 38,34 por 100 de los gastos generales universitarios y el 78,71 por 100 de los salarios destinados a los docentes. Datos obtenidos a partir de 11 calas efectuadas en los Libros de Cuentas con una periodicidad de cinco años, comenzando en el ejercicio contable $1700 / 01$ y concluyendo en el curso $1750 / 51$; A.U.S. 1.384-1.433.
} 
y enquistaban actitudes mentales de carácter conservador, opuestas a cualquier tipo de apertura y pérdida de privilegios.

Los catedráticos propietarios, además de un estipendio fijo, percibían cada año el denominado «residuo»; consistía éste en una participación directa de cada docente en los ingresos universitarios por razón de tercias, participación que era proporcional al número de florines (unidad de cuenta) señalados a cada cátedra regentada en cuestión. Para su obtención, primero se descontaban del montante de los arrendamientos anuales de tercias, con mucho la partida más importante del cargo universitario ${ }^{3}$, determinados desembolsos relacionados con el uso y disfrute de la exacción decimal, el asignado fijo o "salario base" que correspondía a los propietarios y otras partidas de menor consideración; seguidamente, la cantidad resultante se dividia en partes iguales entre el arca y los catedráticos florinistas; y por último, se repartía entre los catedráticos de propiedad la parte que les correspondía de la división, añadiendo previamente el importe de los salarios fijos antes descontados.

La constitución XXX del pontífice Martín $V$ del año $1422{ }^{4}$, que refiere con minuciosidad el reparto de las rentas del Estudio, establecía que se procediese a la partición una vez efectuados los gastos generales de la institución; sin embargo, los descuentos practicados por la Universidad con anterioridad al reparto sólo cubrian parcialmente dichos gastos, por lo que tenemos que concluir que los propietarios detraían importantes cantidades a la Universidad que hubiesen servido para atender sus necesidades.

La reforma hacendística que quiso imponer el doctor don Francisco de Ochoa de Mendarózqueta y Arciamendi, cancelario de la Universidad, por medio del auto de 30-X-1702, pretendía hacer respetar la ley univer-

3 Las rentas de tercias constituyen el componente más importante de los ingresos universitarios, determinando la evolución cuantitativa de los mismos. Representaban el 84,81 por 100 del cargo general en los años encuestados de la primera mitad del siglo xvil. Idem.

4 Las Constituciones del Pontífice Martín V, otorgadas a la Universidad de Salamanca en 1422. y los estatutos de los visitadores reales del Estudio (Covarrubias, año 1561; Zúñiga, 1594; Caldas, 1604; y Gilimón de la Mota, 1618), básicamente, constituían la normativa por la que se gobernaba el Estudio salmantino hasta las reformas de 1771 . El conjunto legislativo fue recopilado e impreso en el volumen Constitvciones apostólicas y estatvtos de la mvy insigne Vniversidad de Salamanca. Recopilados nuevamente por su comisión. En Salamanca, impreso en casa de Diego Cvsio, año M.DC.XXV. B.U.S. (Biblioteca Universitaria de Salamanca) 57.179, 57.180, 57.191 y 57.192

Disponemos de dos recientes ediciones de la legislación universitaria salmantina más importante: Rodriguez-SAN PEdRo, L. E., (estudio y edición), Estatvtos hechos por la Universidad de Salamanca (1625). Salamanca 1990. Valero Garcia, P. y Pérez Martín, M., (edición y estudio), Constituciones de Martin V. Salamanca 1991. 
sitaria, como era su obligación, y descargar al arca universitaria de la mitad del importe de gastos tan importantes como la remuneración de los lectores no propietarios y las obras de la Universidad (partidas no descontadas antes de la partición), a costa de la parte que correspondería a los catedráticos de propiedad.

El auto emitido por el maestrescuela y cancelario notificaba a los contadores mayores, contador menor y demás oficios y nombramientos con intervención en las cuentas universitarias que, bajo severas penas, ajustaran las cuentas del siguiente modo: previamente a la división y repartición del cúmulo común de rentas de tercias entre el arca y los catedráticos de propiedad, habrian de bajarse y descontarse del caudal común los sueldos oficiales de las cátedras de propiedad y de regencia, sin distinción; y del mismo modo, todos los gastos de obras de iglesias y Escuelas, comisarios, pleitos, subsidio y excusado, y demás desembolsos ordinarios y extraordinarios que se relacionasen con las rentas de tercias. La medida tenía carácter retroactivo ${ }^{5}$.

El auto del cancelario pretendía aplicar con rigor lo dispuesto por la constitución XXX del pontífice Martín V. Los catedráticos de propiedad, y los otros claustrales con ellos, consideraban que era el propio cancelario el que, excediéndose en sus atribuciones, pretendía hacer novedad y alterar constituciones y estatutos, práctica y costumbre.

Las dos partes se escudaban en la legalidad, acusándose recíprocamente de actuar contra la ley. En realidad, el problema radicaba en la interpretación de la tan manida constitución martiniana.

El cancelario entendía que debían descontarse del cúmulo común de rentas de tercias, con anterioridad a la división que se realizaba entre los catedráticos y el arca, dos cuantiosas partidas: la renumeración de los lectores no propietarios y las obras universitarias. Ello permitiría al arca de la Universidad ahorrar la mitad del importe de ambas cuantías, o lo que es lo mismo, recaería su pago a partes iguales entre los catedráticos propietarios florinistas y el arca.

En cambio, la práctica seguida en las cuentas era descontar en concepto de salarios de catedráticos exclusivamente la asignación oficial que correspondería a las cátedras de propiedad, y en concepto de obras, la contribución al mantenimiento de las iglesias del obispado. Práctica que obedecería a una interpretación a la letra de la constitución martiniana

5 Un tanto simple del auto se transcribe en el acta de la sesión de claustro de diputados de 3-XI-1702. Vid. Libros de claustros, A.U.S. 170, fs. 57v-59. 
consistente en identificar las lecturas que han de remunerarse con las cátedras de propiedad florinistas, las únicas existentes en tiempos de la reglamentación medieval; y contraer los descuentos por obras a las reparaciones de las iglesias parroquiales, las únicas relacionables con la percepción decimal.

La interpretación del cancelario es más razonable que la de los catedráticos. Otorgaba a la normativa constitucional una proyección futura, actualizaba su vigencia. En cambio, los catedráticos de propiedad impedian cualquier flexibilidad interpretativa, por muy modesta y limitada que fuera. En este caso, el interés del grupo antecede al bien común: en el transcurso de casi trescientos años, en paralelo al creciente control de los propietarios de los órganos de gobierno universitarios, han ido gravando progresivamente al arca universitaria al no efectuarse los descuentos obligados del cúmulo común de rentas (gastos de obras, redenciones de censos y pensiones, compra de libros, otras cargas y gastos), previamente a la partición de los ingresos por tercias en dos mitades.

O de otra forma entendido, el interés de grupo y del común se funden. En el recado que hizo llegar la Universidad al cancelario, en un último intento en balde para que éste anulase las órdenes dadas, podemos leer:

\begin{abstract}
"Habiendo tenido noticia del autho que $V$. S. se à seruido de dar en orden a la quenta y repartimiento de sus rentas, de cuia execución se seguiría tan notable y tan notorio detrimento a la que la misma Vniuersidad considera y á considerado siempre por la más noble y más venerable parte de sí misma, esto es, a sus cathedráticos de propiedad, sin cuia debida y decente manutención ni ella podía subsistir ni su decoro podía ser el mismo que a sido, no sólo muchos años a sino algunos siglos.... ${ }^{6}$.
\end{abstract}

La reforma en las cuentas que quiso imponer el cancelario no salió adelante. El claustro de diputados encargó a una junta de comisarios de distintas facultades, al síndico y a los agentes de Salamanca y Madrid, la defensa judicial en las cortes de Madrid y Roma de la formación de cuentas acostumbrada. La polémica surgida desaparece repentinamente en las actas de las sesiones y la distribución de las rentas siguió efectuándose como se acostumbraba ${ }^{7}$.

Al fin la reforma no cristalizó porque no fue admitida por los claustrales, encabezados por los catedráticos propietarios. El resto de los compo-

Ibidem, A.U.S. 171, fs. 8, 8v.

Para seguir el desarrollo de los acontecimientos sobre la pretensión del cancelario don Francisco de Ochoa cf. Ibidem: A.U.S. 170, fs. 42-43, 44-45, 46v-51v, 57v-60v; A.U.S. 171, fs. 7-11v. 
nentes del cuerpo universitario consentían la transgresión ya que esperaban beneficiarse algún día de ella, o al menos esa era la aspiración de los regentes temporales, profesores y estudiantes ${ }^{8}$. De haber fructificado las medidas que quiso imponer secamente el cancelario, el establecimiento docente hubiera conseguido una mayor racionalización en el reparto y disfrute de las rentas universitarias; se habrían limado las diferencias de los estipendios de los catedráticos (cátedras de propiedad/ cátedras temporales); y si se hubiera obtenido, potencialmente, un importante fondo de reserva anual al que recurrir ante cualquier acontecimiento futuro, como pudiera ser la financiación de las reformas ilustradas. El doctor don Francisco de Ochoa de Mendarózqueta y Arciamendi no pudo imaginar el impresionante alcance que hubiera podido tener la reforma que nació de su celo vigilante.

\section{NUEVOS CRITERIOS EN LA PROVISIÓN DE CÁTEDRAS}

Consideraremos ahora aquellas disposiciones legales emanadas del Rey en las primeras décadas del siglo xvIII, tendentes a la valoración del mérito de los opositores en los concursos para proveer las cátedras universitarias.

El sistema de provisión de cátedras dependiente del Consejo Real establecido definitivamente en la Universidad de Salamanca en el año 1641, con el que se pretendía solucionar los problemas de corrupción y violencia generados por las votaciones de estudiantes en las que se basaba el sistema de provisión anterior, había dado paso a nuevos abusos e irregularidades en la selección del profesorado, a nuevas corrupciones y desigualdades de trato. Los criterios de antigüedad (de grado, beca y cátedra) y de experiencia académica (medida en años de dedicación y número de ejercicios literarios) presidían los informes de méritos de los opositores que la Universidad remitía al Consejo. En la adjudicación de los puestos docentes se consideraban también los ascensos regulares de los catedráticos y la alternancia de cada uno de los colegios mayores de Salamanca con el conjunto de los restantes estudiantes universitarios en la provisión de las cátedras jurídicas (turno colegial) ${ }^{9}$.

8 En la aclaración comprendida en el acuerdo de claustro pleno de 25-IX-1702 se expresa: "... la qual es causa común de la Vniuersidad y ella es la parte formal, y no algún particular, por estenderse los intereses de dichas rentas así a los cathedráticos de propiedad actuales como a los futuros, y a todos los actuales cathedráticos de regencia y pretendientes a cáthedras, pues todos aspiran y son oppositores a las cáthedras de propiedad..." ibidem, A.U.S. 170, ts. $49,49 \mathrm{v}$.

9 Consúltense las listas impresas de los opositores a cátedras, con sus méritos literarios, 
Las órdenes reales tenian por objeto limar las asperezas de un método de selección de los catedráticos que había quedado desvirtuado en medio siglo. En las primeras décadas del siglo XVIII se expiden repetidos mandatos, dirigidos a los consejeros reales y a las universidades mayores, para que el mérito se valorase más que la antigüedad de grado o beca en las provisiones de cátedras, que conducirían al deseado fin de los privilegios colegiales y a la desaparición del turno en la salmantina ${ }^{10}$. Me estoy refiriendo al auto fechado en Madrid a 26-IX-1708, dirigido a los rectores de las universidades mayores de Salamanca, Valladolid y Alcalá ${ }^{11}$; a las resoluciones de Felipe $V$, a consultas del Consejo de 12-V$1714^{12}$ y $21-V I I I-1716^{13}$; a la carta orden del Consejo Real expedida en Madrid, a 17-XI-1717, y enviada al vicerrector de la Universidad salmantina ${ }^{14}$; y a la resolución real emitida en San Lorenzo, a $20-\mathrm{X}-1721^{15}$.

El caudal legal no produjo resultados positivos. La pretensión real de hacer más rigurosas las oposiciones a cátedras y más justas, potenciando el mérito y la igualdad de oportunidades, no se materializó, y el turno y la antigüedad siguieron siendo los criterios más valorados en la adjudicación de los puestos docentes.

Comprobamos en las medidas legales una confrontación a tres bandas: Rey y círculo manteísta, que impulsan la reforma; Consejo Real y círculo colegial, que la frenan; y la Universidad de Salamanca, receptora pasiva de la normativa. La rápida confrontación se salda con la inaplicación de las iniciativas reformistas que se querian implantar a golpe de decreto y con la consolidación de un sistema de selección del profesorado que haría reproducir indefinidamente las posiciones de privilegio de los colegiales mayores en las cátedras universitarias, y consiguientemente, en los pues-

cosidas en los Expedientes de Procesos de Cátedras, A.U.S. 1.002-1.011. Vid. también el Libro de Posesiones y Provisiones de Cátedras, A.U.S. 956.

10 Las órdenes se completaban con otras disposiciones menos conflictivas que buscaban agilizar los nombramientos y posesiones de los catedráticos y corregir otros excesos en las oposiciones (estancias de los opositores en la Corte, ausencias de los mismos en los ejercicios de oposición), para que la enseñanza en las aulas se interrumpiera lo menos posible.

11 La copia del decreto se leyó en claustro de diputados de 17-X-1708 y fue obedecido por la Universidad. Cf. Libros de Claustros, A.U.S. 176, fs. 86, 86v. Novísima Recopilación, libro VIII, título IX, ley $\mathrm{V}$, nota 4 .

12 Se hacía saber al Estudio salmantino por carta orden expedida en Madrid, a 7-1X-1714. Cf.: Libros de Claustros, A.U.S. 182, fs. 72-75. Novísima Recopilación, libro VIII, título IX, ley XX.

13 La carta orden (26-IX-1716) que informaba del decreto fue leida y obedecida err claustro de diputados de 3-X-1716. Libros de Claustros, A.U.S. 183, fs. 86v-87v. Novisima Recopilación, libro VIII, título IX, ley XXI.

14 La copia de la carta de halla en Libros de Claustros, A.U.S. 185, fs. 5v, 6.

${ }_{15}$ Novísima Recopilación, libro VIII, título IX, ley VI. 
tos de gobierno y dirección. Tal sistema, que cristalizaría a mediados del siglo XVII y se prolongaría hasta el amanecer de las reformas ilustradas, tendría una doble manifestación: por una parte, el favoritismo mostrado hacia los colegiales mayores por el Consejo de Castilla y el Consejo de la Cámara, organismos controlados tradicionalmente por excolegiales, en el otorgamiento de los premios literarios y políticos, respectivamente; por la otra, y refiriéndonos exclusivamente al marco salmantino, el procedimiento del turno (en la provisión de las cátedras de Derecho) y de la alternancia de los cuatro centros (en la provisión de las de Filosofía y Teología), para evitar el choque de intereses entre las comunidades mayores en el único centro universitario donde podía producirse.

La institucionalización de la injusta provisión de cátedras, en conexión con la distribución de los más altos empleos desde Madrid, benificiaría a los colegiales mayores. En la Universidad de Salamanca monopolizaban las cátedras jurídicas y compartían el dominio numérico, con los religiosos, en la agrupación de las plazas docentes de Artes/Teología; en definitiva, tenían asegurada su presencia en las cátedras más prestigiosas, mejor remuneradas y de mayor proyección, con lo que copaban las salidas hacia los altos cargos en audiencias y chancillerías, y hacia las canonjías y obispados. El resto de los graduados consiente la desigualdad de trato, de la que son responsables autoridades e instituciones.

\section{REPLANTEAMIENTO DE LOS OBJETIVOS EDUCATIVOS UNIVERSITARIOS}

De las aulas universitarias salían las élites sociales que iban a dirigir las vidas, en todos los sentidos, de los súbditos de la Corona. Cuando su formación intelectual no se ajustaba a todos los planteamientos gubernamentales, por coyunturales que fueran éstos, se producía un desajuste funcional que era preciso solucionar de algún modo.

Cuatro cartas órdenes del Consejo Real expedidas en el año 1713, firmadas por el abad de Vivanco y remitidas a la Universidad de Salamanca, contenían las líneas generales de un programa educativo con aires nuevos que quería ser llevado al Estudio salmantino y que implicaban una reforma en los estudios. El Consejo, a través de sus escritos, diseñaba la preparación intelectual de los grupos sociales que debían sostener, desde pusiciones destacadas, el Estado: deseaba juristas avezados en el derecho real y textos conciliares, para sentenciar adecuadamente los pleitos; teólogos formados en la Teología positiva y dogmática para hacer frente a la herejía y los errores dogmáticos; y una nobleza educada. EI nuevo diseño educativo del Estado, que no sólo tenía razones prácticas, 
formar buenos letrados, sino que afectaba a la misma concepción de la sociedad sobre la que se erige, se expresaría fugazmente en este año haciendo pronunciarse a la salmantina sobre la modificación de su programa educativo.

Era el momento propicio, el fiscal general del Consejo de Castilla, Melchor de Macanaz, inspiraba las reformas, que formaban parte de un conjunto de medidas a nivel académico y administrativo (años 1713-1715), tendentes a remozar la administración de justicia y los estudios universitarios y a disminuir la fuerza de los antiguos colegiales mayores en la burocracia estatal. De la actuación de Macanaz en el ámbito universitario se desprende un aumento del intervencionismo regio en las universidades $y$ un intento de imponer medidas uniformadoras.

El Consejo, haciéndose eco de la preocupación real, se interesaba por la preparación de los ministros que regentaban plazas en tribunales, audiencias y chancillerías, considerando deficiente la enseñanza universitaria basada en el Derecho romano y pontificio de contenidos teóricos. A tal fin se dirigía a las universidades mayores con el objeto de que potenciaran la impartición de un Derecho práctico y actual, de raíz nacional.

Por carta orden fechada en Madrid, a 29-XI-1713, remitida también a las universidades de Valladolid y Alcalá, se solicitaba al Estudio salmantino un informe para que en sus cátedras de la facultad de Leyes se leyesen principalmente las leyes patrias, que son "aquellas leyes por las quales se deben determinar los pleitos en estos Reynos" ${ }^{16}$. Otra carta orden (en Madrid, a 5-XII-1713), de fuerte contenido regalista y también dirigida a las otras universidades mayores, requería a la Universidad salmantina un nuevo informe para que en las cátedras de Cánones se leyesen concilios nacionales y generales, primera disciplina de la Iglesia y leyes reales copiadas del Derecho canónico y concordantes ${ }^{17}$. En ambos casos, el sentido de la preparación profesional de la enseñanza universitaria impregnaba los documentos ${ }^{18}$.

16 Copiada en el acta de la sesión de claustro pleno de 2-XII-1713. Libros de Claustros, A.U.S. 182 , fs. $3-4$.

17 Leída en claustro pleno de 3-1-1714. Ibidem, A.U.S. 182, fs. 22v-24.

18 Respecto a la primera resolución se dice: “... y pudiendo haber entendido el Consexo por el fiscal general el grabe escrúpulo en que está la delicada conzienzia del Rey porque los cathedráticos y profesores pasen la flor de su vida en el estudio del Derecho ziuil de los romanos, mirando nuestras patrias leyes con desdén y aun desprezio, yncapacitándose así de salir de las vniuersidades y colegios a rregentar los empleos de juezes en las chanzillerías, audienzias y tribunales donde prezisamente deben sentenziar según las leyes del Reyno y con zierta notizia y conozimiento de ellas, y de ninguna manera por el Derecho ciuil, ha âcordado..." Ibidem, A.U.S. 182, fol. 4. Respecto a la segunda: “...sucede también que los cathedráticos y profesores de los sagrados Cánones suelen vir de los que verdaderamente lo son y gastar su 
Las respuestas se encargaron a los graduados juristas, siendo aprobadas, respectivamente, en los claustros plenos de $3-1$ y $29-1$ de $1714^{19}$.

En el informe concerniente a las Leyes se indicaría que la práctica sería enseñada y leída en dos cátedras de Prima y Víspera de Leyes, alternando cada año con las otras dos restantes de idéntica nominación; y que la cátedra de Volumen ya recogía esta enseñanza práctica ${ }^{20}$. Se acuerda, además, que las nuevas asignaturas comiencen a impartirse a partir del curso $1714 / 15^{21}$.

En el informe relativo a Cánones se expresaría que los catedráticos darían las nuevas enseñanzas completando las explicaciones de las asignaturas estatutarias. Se proponía, además, la conversión de la cátedra de Decretales Mayores en cátedra de Decreto Menor, con la misma lectura señalada al catedrático de Decreto (pasaría a denominarse Decreto Mayor) ${ }^{22}$.

Si en las facultades jurídicas se decidió la introducción de nuevas materias, aunque fuera tímidamente y compaginándose con las lecturas de Derecho tradicionales, la propuesta de modificación de los estudios teológicos fue rechazada de plano por los teólogos y universitarios.

En carta orden del Consejo Real fechada en Madrid, a 9-XII-1713, que debió enviarse igualmente a otras universidades, se solicitaba al Estudio salmantino información sobre una representación hecha llegar al mismo Consejo en la que se criticaba la utilidad de la Teología metafísica de escuelas y religiones que imperaba en los generales universitarios. El Consejo era receptivo a la idea en una enseñanza teológica basada en el estudio de las obras de los Santos Padres de la Iglesia y de los principios de la religión católica, y en la explicación de la Sagrada Escritura ${ }^{23}$.

tiempo, estudio y aplicazión en las materias que v́nicamente tocan a la jurisdiczión ecclesiástica. Y como los más de ellos esperen salir de sus cáthedras ô profesión a las plazas de ministros de las chanzillerías, audienzias y tribunales, se experimenta estar mui capazes en las materias para gouernar eclesiásticos pero mui agenos de las que tocan â su ministerio y encargo, nezesitando por esta causa, después de perdida la salud y la flor de su vida en dichos estudios. hazer vno nuebo para el cunplimiento de su obligazión." Ibidem, A.U.S. 182, fs. 23, $23 \mathrm{v}$.

19 Ibidem, A.U.S. 182 , fs. $21 \mathrm{v}-22 \mathrm{v}$ y $36-37$, respectivamente.

20 Cf. ibidem, A.U.S. 182, fs. 3-4, 10-13v, 20, 20v, 21v-22v. El Consejo, en carta orden de $7-\mid X-1714$, dada en Madrid y firmada por el abad de Vivanco, insistiría en que la Universidad cumpliera con lo informado. Ibidem, A.U.S. 182 , fs. 72-75, 77-78. Una posterior resolución del Consejo (comunicada por carta orden librada en Madrid, a 15 de noviembre de 1741), reiteraría la obligación de enseñarse simultáneamente el derecho común y real. Ibidem, A.U.S. 208, fs. $98 \mathrm{v}-101 \mathrm{v}$.

${ }^{21}$ Ibidem, A.U.S. 182, fol. 78. Acuerdo de la junta de juristas de la facultad de Derechos de 23-IX-1714.

22 Vid. ibidem, A.U.S. 182 , fs. $22 v-24,31 v, 32,33 v-35,36-37$

${ }_{23}$ La carta se inserta a la letra en el acta de la sesión de claustro pleno de 18-XII-1713. Ibidem, A.U.S. 182, fs. 14-15. 
Los graduados en Teología, de actitud conservadora y dolidos por entender que la propuesta desacreditaba a la facultad, prepararon una respuesta contundente en defensa de la Teología escolástica, tenida por dogma:

"Se diga la Theología scholástica como hasta aquí por ser vtilíssima i declararlo así todos los authores cathólicos, cuia vtilidad juzga la facultad de Theología de Salamanca que es dogma; i que los dichos cathedráticos de Theología, conformándose con la boluntad de Su Magestad, leerán i enseñarán la Theología scholástica como siempre se ha hecho, impugnando todos los dogmas falsos de los herejes, hasta oy siempre executadon ${ }^{24}$.

La Universidad aprobaría en sesión plenaria de 31-III-1714 el informe presentado, adjetivándolo de «grauíssimo, doctíssimo y authorizado» 25 .

Por último, el Consejo Real se interesaba porque la nobleza principal de la monarquía que no siguiese la carrera universitaria, recibiese una educación afín a su condición social. Había pensado en la Universidad salmantina, y más concretamente en el Colegio Trilingüe que ésta tutelaba, para la erección de un centro educativo especial que ofreciese la enseñanza de las artes liberales y permitiese maestros de armas, música, danza, juegos de raqueta, trucos y ejercicio de maestranza, al modo de los de Bolonia, Roma y franceses. Los colegiales pagarían una pensión anual a estipular. Y así lo hacía saber a la Universidad por medio de carta orden librada en Madrid, a 9-XII-1713 ${ }^{26}$.

Una junta compuesta por graduados de todas las facultades estudiaría la iniciativa. En principio, la junta y el claustro universitarios eran favorables a la fundación de un colegio de estas características en Salamanca, pero no en que se erigiera en el Colegio Trilingüe, destinado a la enseñanza del Griego, Retórica y Hebreo ${ }^{27}$. El seminario de nobles se fundaría finalmente en la Corte y contaría con el favor real ${ }^{28}$.

24 Ibidem, A.U.S. 182, fs. 26v, 27.

25 Vid. ibidem, A.U.S. 182, fs. 14-16, 26v, 27, 41-43v.

${ }^{26}$ Inserta en el acta de la sesión de claustro pleno de 18-XII-1713. Ibidem, A.U.S. 182, fs. 15-16.

27 Vid. ibidem, A.U.S. 182 , fs. 15-16v, 19v-21, 24v-26, 27-31v, 115-116v.

28 Se erige y funda el Real Seminario de Nobles de Madrid por decreto de Felipe $V$ de 21 de septiembre de 1725, en San IIdefonso. Novisima Recopilación, libro VIII, título III, ley I. Por real resolución de 18-IV-1755, comunicada a la Universidad de Salamanca por carta orden de 26-IV-1755, dada en Madrid, se ordenaba a las universidades el reconocimiento de los cursos de Filosofía que hubiesen hecho los seminaristas. Fue obedecida en claustro pleno de 9-VII1755. Libros de Claustros, A.U.S. 222, fs. 80,81 . 
Las reformas universitarias no se consolidaron, en lo que contribuyó decisivamente la caída de Macanaz y su equipo. Las presiones ejercidas por consejeros, colegiales mayores y personalidades de la Corte, lograron su objetivo de que no prendiera la reforma en la Universidad y la administración ${ }^{29}$.

\section{REFORMA EN LOS COSTES DEL DOCTORADO Y MAGISTERIO}

La reforma también podía provenir de los mismos estudiantes, en este caso de los graduandos, a través de su actuación encaminada a superar una normativa universitaria perjudicial a sus intereses. La necesidad de un movimiento irrefrenable, cierta laxitud claustral y la receptividad de las máximas instancias gubernativas se combinaron para que, excepcionalmente, tuviera éxito, aunque limitado, la modificación de las pautas tradicionales en la Universidad de Salamanca.

Los altos costes de los grados universitarios ${ }^{30}$, particularmente los de doctor y maestro, los hacía restrictivos ${ }^{31}$. Pocas economías se podían permitir largos años de estancia en la ciudad y los cuantiosos desembolsos por las tasas y derechos, en moneda y en especie, de las graduaciones ${ }^{32}$ : un grado de bachiller podía costar a principios del siglo XVIII

29 Cf.: Fayard, J., Los miembros del Consejo de Castilla (1621-1746). Madrid 1982, págs. 55, 56, 62-64, 77. Martín GaIte, C., El proceso de Macanaz. Barcelona 1988, págs. 187-190, 222,223 . SALA BALUST, L., Reales reformas de los antiguos colegios de Salamanca anteriores a las del reinado de Carlos III. Valladolid 1956, págs. 52-59.

${ }^{30}$ La Universidad de Salamanca, como las otras mayores, ofrecía tres grados: bachiller, licenciado y doctor (en Cánones, Leyes y Medicina) o maestro (en Teología y Artes). El primero capacitaba para el ejercicio de una profesión, como en nuestros días la licenciatura, aunque para ciertos desempeños era suficiente el comprobante de la realización de los cursos. El grado de licenciado significaba la máxima capacitación académica del graduando, mientras que el doctorado no era más que un revestimiento honorífico y formal de dicha capacitación. El grado de bachiller era requisito imprescindible para opositar a las cátedras universitarias. Los dos últimos, los grados mayores, se exigían a todo docente universitario que regentase una cátedra de propiedad y abrian las puertas a los puestos de mayor prestigio en la administración civil y eclesiástica.

31 En la primera mitad del siglo xVHI, por ejemplo, se otorgaron en la Universidad de Salamanca 3.712 titulaciones de bachiller, 359 de licenciado y 243 de doctor/maestro (incluidos 82 maestros de Teología incorporados). Únicamente el 4,10 por 100 de los inscritos en los libros de matrículas del período eran bachilleres, el 0,38 por 100 licenciados y el 0,26 por 100 doctores/maestros. Si tomamos como punto de referencia a los bachilleres (base 100), sólo el 9,48 por 100 se graduarían de licenciado y el 6,54 por 100 de doctor. Si partimos de los licenciados, el 69,03 por 100 se doctorarian. Cf.: Libros de Grados de Bachiller, A.U.S. 754 y 758 . Libros de Grados Mayores, A.U.S. 790-796. Nos estamos refiriendo a grados conferidos.

${ }^{32}$ Las ceremonias de graduación de doctor o maestro, sufragadas por el graduando o graduandos, consistian en el paseo universitario en la tarde de la víspera del grado, al que 
entre 122 y 220 reales de vellón, dependiendo de la facultad; la cifra subía a 1.035 reales, más gastos en especie, en los licenciamientos; y se disparaban a 3.588-9.025 reales, más pompa, en los doctoramientos y magisterios. Los grados mayores podían significar al graduando un gasto que oscilaba entre 20.000 y 30.000 reales, e incluso más ${ }^{33}$.

El carácter restrictivo de los grados los hacía elitistas, y por tanto prestigiosos, en correspondencia con la valoración intelectual y profesional que tenían estos títulos; y representaban percepciones añadidas en forma de propinas, agasajos y regalos a los graduados, que serían bien recibidos por los catedráticos peor remunerados y los eternos opositores. Los grados mayores, licenciado y doctor/maestro, manifestaban, consecuentemente, el carácter gremial, corporativo y selectivo de la profesión docente.

Los graduandos procuraron, por todos los medios, reducir los costes de los últimos grados, en lo que concernía a la pompa, a pesar de rozar la legalidad o incumplirla; contaban para el logro de sus intenciones de la tolerancia de los claustrales, unas veces, y con el apoyo de las instancias de poder en la Corte. Así, la Universidad consentía que sus catedráticos propietarios se graduasen fuera de plazo ${ }^{34}$. Los religiosos, tras

seguian el refresco, distribución de colaciones y cena copiosa en una pieza del Colegio Trilingüe. Al dia siguiente, una vez conferido el grado o los grados en la catedral nueva, para lo que se levantaba un suntuoso escenario, se desarrollaba la fiesta de toros en la Plaza Mayor de la ciudad con colaciones y refresco incluidos. A esto se añadía la tasa de propinas destinadas a autoridades, graduados y ministros, común a todas las graduaciones pero de cuantía diferente según la facultad de que se tratara. En los magisterios de Teología y Artes se aligeraba la ceremonia por su talante eclesiástico: no existían cena, colaciones ni toros; en los segundos tampoco se regalaban guantes. Para que los grados de doctor de Cánones, Leyes y Medicina se confirieran sin pompa, habrá de conseguir el interesado la oportuna real provisión del Consejo de Castilla, que deberá presentarse en secretaría. El graduado en tiempo de lutos reales sólo pagaba por propinas y estrados. En las incorporaciones de maestro en Teología, el incorporante sólo pagaba las propinas correspondientes. Vid. Zeremonial Sagrado y Político de la Vniversidad de Salamanca compuesto y arreglado a sus estatutos y loables costumbres, con reformazión de algunos abusos, B.U.S. Ms. 333, capítulos 9-13.

33 Para establecer estimaciones aproximativas de los costes de los grados universitarios hemos acudido a la normativa oficial, al arancel de derechos de secretaria actualizado en el año 1702 y a los libros de grados. Cf.: Constituciones de Martin V (1422), constituciones XVII, XVIII, XX, XXXI; Recopilación de Estatutos (1625), títulos 30 y 32. Libros de Claustros, A.U.S. 170 , fs. 30-34. Libros de Grados Mayores correspondientes a la primera mitad de siglo, bajo las signaturas A.U.S. 790-796. Ver también Manuscrito anónimo, A.U.S. 2.886, fs. $68 \mathrm{v}, 69,74,74 \mathrm{v}$, $82 \mathrm{v}, 83,95,95 \mathrm{v}$.

${ }_{34}$ Los estatutos precisaban a los catedráticos que regentasen una cátedra de propiedad a graduarse en dos años de licenciado y doctor o maestro, so pena de privación de la cátedra. Con este fin se había prescrito que una parte considerable de sus remuneraciones permaneciera en depósito para financiar las costosas graduaciones. Recopilación de Estatutos (1625), título 32 , estatutos 65 y 66 (Gilimón de la Mota, 1618). 
licenciarse en la salmantina, incorporaban el grado de maestro obtenido en una universidad cercana (muy a.menudo, Santo Tomás de Ávila), ahorrándose ciertas sumas del gasto ordinario. También eran frecuentes las graduaciones conjuntas o en tiempos de lutos reales, para reducir gastos.

Precisamente, el hecho de que se burlara habitualmente la normativa concerniente al conferimiento de los grados de doctor y maestro, obligó a la Universidad a proponer al Rey una cierta reducción de los gastos ceremoniales (que no incluía la eliminación de la pompa) ${ }^{35}$. La iniciativa, a pesar de sus matices conservadores, tuvo buena acogida en Madrid y daría lugar a la real cédula de Fernando VI de 11 de enero de 1752, completada con órdenes posteriores del mismo año y 1754, por la que suprimía la pompa en la colación de los grados de doctor y maestro salmantinos, rebajándose sustancialmente los gastos de estas graduaciones.

La real cédula del año 1752 (Buen Retiro) manda cesar "en todo" la pompa acostumbrada en los grados de la Universidad: el paseo se confina dentro de los patios de Escuelas; los dispendios en especie se reducen a un único refresco (que ha de dar el graduando o los graduandos siendo graduación conjunta) de dos bebidas, y a dos libras de dulces para cada graduado y una para los ministros asistentes. Los doctores y maestros continuarían cobrando las propinas monetarias estipuladas en la tasa, sin añadidos por ningún otro concepto. Se elimina el festejo de toros. Finalmente, se ordena al Consejo no conceder el año de prórroga para graduarse a los catedráticos de propiedad ${ }^{36}$.

35 El detonante fue la presentación en claustro, en el año 1750, de diversas provisiones reales ganadas a instancia de varios graduandos, en las que se les dispensaba la pompa en los grados de doctor que iban a celebrarse por los lutos publicados a la muerte del rey de Portugal Juan V. La Universidad, ante tal situación, decide suplicar al Rey y representar al Real Consejo la celebración de las graduaciones mayores con pompa, expresando la voluntad de formar un arreglo de reducción de gastos en los grados mayores que sería remitido en fecha próxima al Consejo para su aprobación. Acuerdo de claustro pleno de 9-IX-1750. Vid. Libros de Claustros, A.U.S. 217, fs. 61-64. Parece ser que la Universidad informó al Consejo en sentido conservador, "exponiendo, enttre otras cosas, quantos fundamentos podían servir de apoio al immemorial vso de la pompa, $/$ Ibidem, A.U.S. 219 , fol. $16 \mathrm{v}$.

36 Se halla reproducida en el acta del claustro pleno celebrado el 27-1-1752. Libros de Claustros, A.U.S. 219, fs. 16-18. Ed.: ARTEAGA ESPERABÉ, E., Historia pragmática e interna de la Universidad de Salamanca. Salamanca 1914 y 1917 (2 vols.) Tomo primero, documento XXV, págs. 919-920. SÁINZ DE ZÚÑIGA, C. M. ${ }^{2}$, Historia de las Universidades Hispánicas. Orígenes y desarrollo desde su aparición a nuestros dias. Madrid, Ávila 1957-1977 (11 vols.). Vol. IV, Cartulario de las Universidades Hispánicas, documento DCCCLXXVIII, págs. 348-349. Vid. Novísima Recopilación, libro VIII, título VIII, ley XV. Ver también ADDY, George M., The Enlightenment in the University of Salamanca. Durham 1966, págs. 86-87. En la orden real se aludía a que los costes del grado superior hacian inaccesible la carrera universitaria a muchos estudiantes. Libros de Claustros, A.U.S. 219, fol. 16 
Dos órdenes posteriores matizarán el mandato, resolverán pleitos y diferencias entre las partes implicadas (cabildo catedralicio y Universidad), y aclararán dudas interpretativas de los claustrales: por real cédula librada en Buen Retiro, a 11 de julio de 1752, se ordenaba que los grados siguiesen confiriéndose en la nave del Evangelio de la Catedral nueva, con la limitación de que no se armase el tablado para la colación de dichos grados más de dos veces al año ${ }^{37}$. Por último, por resolución a consulta del Consejo de 5 de marzo de 1754, se resuelven dos interrogantes planteados por la Universidad: respecto al primero, relativo al gasto de refresco y dulces en los magisterios de Teología y Filosofía, se suprimen los refrescos en los doctoramientos, estableciéndose en su lugar la obligación de dar el graduando, con otros o por separado, 8 reales y dos libras de dulces a cada graduado, y la mitad a los ministros asistentes, en los grados de Derechos y Medicina; y 4 reales y 1 libra, la mitad a los ministros, en los magisterios de Teología y Artes. Con relación al segundo, concerniente al plazo de graduación de los catedráticos de propiedad, se establece que los docentes propietarios tendrán necesariamente que haberse graduado a los dos años de haber obtenido la cátedra, hayan percibido o no la totalidad de su renta ${ }^{38}$.

Con respecto a años anteriores se habían eliminado los refrescos, merienda, cena, gran parte de las colaciones y ciertas propinas en moneda relacionadas con la pompa, que podrian suponer un abaratamiento aproximado del 50 por cien en el importe final. A pesar de ello, los grados mayores siguieron siendo caros y prohibitivos para una gran mayoría de la población universitaria sin disponibilidades económicas. El grado mayor continuaba estando cerrado al estudiante común, y con él, la cátedra, y con ella, toda aspiración profesional destacada.

${ }^{37}$ Cédula real incluida y obedecida en el acta de la sesión plenaria de 17-VII-1752. Libros de Claustros, A.U.S. 219, fs. 64v-70v. Ed.: Esperabé ARTEAGA E., Historia pragmática..., op. cit., tomo primero, documento XXVIII, págs. 921-923. Aso y SÁinz DE ZúñIGA, C.M. ${ }^{\star}$, Historia de las Universidades..., op. cit., vol. IV, Cartulario de las Universidades Hispánicas, documento DCCCLXXIX, págs. 349-350.Vid. Novísima Recopilación, libro VIII, título VIII, ley XV, nota 11.

${ }_{38}$ También se prohibian los músicos. El real decreto está inserto en una carta orden del Consejo fechada en Madrid, a 10-IV-1754. Libros de Claustros, A.U.S. 221, fs. 26-27. Vid. Novisima Recopilación, libro VIII, título VIII, ley XV. El real decreto fue obedecido por la Universidad en claustro pleno de 26-IV-1754. Ver Manuscrito anónimo, A.U.S. 2.886 , fs. 78 v-81.

Un acuerdo posterior de claustro pleno de 30-X-1759 estableció que no se diesen dulces ni pesetas en grados de doctor y maestro con lutos, despejando las dudas ofrecidas con motivo de tres próximas graduaciones que iban a celebrarse en los lutos publicados por la muerte del rey Fernando VI. Libros de Claustros, A.U.S. 221, fs. 90-91

Información sobre la supresión real de la pompa en los grados de doctor y maestro salmantinos en Libros de Claustros: A.U.S. 217. fs. 61-64, 66v-70v, 71v-73v, 74v-77, 80v-85, 120-122v, 124, $124 v$; A.U.S. 218, fs. 4-5v; A.U.S. 219, fs. 15v-19v, 21-22v, 64-71v, 104v-106, 118-119v; A.U.S. 220 , fs. $34 v-38$; A.U.S. 221 , fs. $26-27,90-91$; A.U.S. 226 , fs. $89 v-91$. 


\section{MATRÍCULA UNIVERSITARIA Y REFORMISMO INSUFICIENTE}

Comprobaremos en este bloque de reformas que las cifras de población universitaria y las reformas en la enseñanza universitaria están íntimamente relacionadas: cuando las primeras tienden a la baja, las segundas se multiplican.

La capacidad de convocatoria de la Universidad de Salamanca había descendido considerablemente, iniciado el siglo XVIII, con relación a épocas anteriores: sus $1.837,07$ matriculados anuales en la primera mitad del Setecientos ${ }^{39}$ estarían muy lejos de los 5.000 a 7.000 inscritos durante la segunda mitad del siglo XVI, en plena fase de expansión universitaria; o de los cerca de 5.000 registrados en el curso 1614/15, años en los que los estudiantes acudían masivamente a las aulas ${ }^{40}$. Las seis primeras décadas del siglo XVIII se situarían en una línea evolutiva plurisecular de descenso continuado de la matrícula universitaria, determinado por la progresiva disminución de las cifras de estudiantes ordinarios o manteístas ${ }^{41}$, que arrancaría en torno a los años 1630-1640 (en sintonía con el declive y estancamiento social general), y se prolongaría hasta entrado el siglo xIX.

Tanto los universitarios como las máximas instancias del poder eran conscientes de que el descenso de la población universitaria constituía el

39 Promedio anual de matriculados corregido, excluyendo repeticiones y duplicaciones. Se ha conseguido a partir del examen detenido de los Libros de Matrícula del período: años 1700/ $01-1750 / 51$, A.U.S. 405-455.

40 Cf. Rodriguez-San Pedro, L. E., La Universidad Salmantina del Barroco, periodo 1598 1625. Salamanca 1986 (3 vols.) Vol. III, págs. 83-89. Idem, «La vida estudiantil en el Siglo de Oro", en La Universidad de Salamanca. Ocho siglos de Magisterio. Salamanca 1991, pág. 75. Rodriguez-SAN PEDRo, L. E., y otros, "Declive y regionalización de la matrícula saimantina de los siglos XVII y XVIII. Aproximación descriptiva”, Stvdia Historica (Historia Moderna), vol. VIII, n. 3 (Salamanca 1985), pág. 146.

4 Nada menos que un total de 1.050,35 colegiales se matriculaban anualmente en el Estudio salmantino a lo largo de la primera mitad del siglo XVIII, frente a 721,27 manteístas. Las cifras de inscripciones están corregidas para evitar repeticiones y duplicaciones. Medias anuales obtenidas a partir del análisis estadístico de los Libros de Matrícula del período. Vid. Libros de Matrícula, años 1700/01-1750/51, A.U.S. 405-455.

Si durante el primer tercio del siglo xvı los manteístas significaban más del 85 por 100 de la población del Estudio, en la segunda mitad de siglo irían declinando hasta desembocar en el 40,71 por 100 de la primera mitad del Setecientos. Paralelamente, la presencia de colegiales seculares y religiosos se intensifica, por lo que podemos concluir que se está produciendo un cambio cualitativo de gran magnitud en la composición social universitaria. Cf. RodRigUEZ SANPedro, L. E., y otros, “Declive y regionalización...”, op. cit., págs. 146-150. Rodriguez SANPedro, L. E., "La vida estudiantil...", op. cit., pág. 76. Polo Rodríguez, J. L., "Estudiantes manteístas salmantinos en la Universidad de Salamanca de la primera mitad del siglo xvIII», Stvdia Historica (Historia Moderna), vol. IX (Salamanca 1991), págs. 23-41. Únicamente tras las reformas carolinas recuperarían los manteistas aquel predominio que ostentaban en el siglo XV! y primera mitad del siglo XVII 
primer exponente significativo de la decadencia de la Universidad. Este fenómeno será su máxima preocupación y el que suscite las reformas, mediante las cuales se intentarán corregir los problemas derivados del descenso global de matriculados y elevar las cifras de estudiantes para restituir, de esta forma, el crédito que la institución docente había perdido.

El primer intento de reforma global universitaria parte del poder. Un decreto (Madrid, 22-11-1718) remitido al Consejo Real e inserto en una real provisión fechada en Madrid, a 26-ll-1718, restablecía inviolablemente en la Universidad de Salamanca la alternativa de las dos escuelas, tomista y jesuítica, en la provisión de las cátedras de regencia y propiedad de Artes, con el objeto de activar la enseñanza en esta facultad ${ }^{42}$; y solicitaba del Consejo remedio al escaso ejercicio docente en el Estudio salmantino y al bajo número de cursantes, que desacreditaban a la institución, sin limitación en cuanto a procedimiento, forma y contenido ${ }^{43}$ :

\begin{abstract}
«Mando que el Consejo se aplique con el mayor desbelo â buscar y proponerme los medios nezesarios y los que parezieren más conducentes y eficazes para poner remedio â tantos males y abusos que de muchos años â esta parte se han experimentado y se están experimentando, no sólo por lo que mira a las cáthedras de Philosofía, sino también de Theología, Cánones, Leyes, Medizina y demás facultades, cuia enseñanza y exercicio en algunas es ninguno, y en muchas y aun en todas, mui corto y de mero cumplimiento y zeremonia; aunque para esto sea nezesario mudar la asignatura de cáthedras, el méthodo de regentarlas, las horas más ô menos que se deuan gastar en la enseñanza pública de cada vna de ellas, ô alterar y mudar los estatutos que se han establezido, ô por el mismo Consejo ô por los visitadores que de mi orden han visitado dicha Vniuersidad; porque, aunque en aquellos tiempos pudieron ser mui v́tiles y aun nezesarios, en los presentes serán acaso muchos de ellos ynútiles y aun perniziosos. Y si en los colegios, expecialmente menores, vbiere algunos desórdenes ô abusos que pidan remedio, también para él me propondrá el Consejo los medios para que se logre en todo el deseado fin en vna Vniuersidad, que siendo vna de las más zelebradas de la Europa, no sólo por los ynsignes maestros que en todas facultades la
\end{abstract}

42 La alternativa era una vieja aspiración de los jesuitas salmantinos y hasta su decreto desencadenó un prolongado debate sobre su conveniencia o no que encendió los ánimos de los claustrales en tormentosas reuniones. Vid. Libros de Claustros, A.U.S. 184, fs. 9-14, 15, 15v, 20-29, 105v-112, 137-148. Ver también CORTINA ICETA, J. L., El siglo XVIII en la Pre-llustración Salmantina. Vida y pensamiento de Luis de Losada (1681-1748). Madrid 1981, págs. 89-162.

${ }_{43}$ La real provisión, con el real decreto inserto, fue leida en claustro pleno de 4-111- 1718 . Libros de Claustros, A.U.S. 185, fs. 32-35. Ver los fs. 35-37v, del mismo libro, para conocer la fría acogida que tuvo por la mayor parte de los claustrales. Ed.: Esperabé Arteaga, E., Historia pragmática..., op. cit., tomo primero, documento LXXXV, págs. 873-875. AJo, G. y SÁinz de ZúNIGA, C.M. ${ }^{\text {, }}$ Historia de las Universidades..., op. cit., vol. IV, Cartulario de las Universidades Hispánicas, documento DCCLXXXVI, págs. 201-203. 
an ylustrado, sino por las gruesas rentas con que éstan dotadas sus cáthedras, se alla oy no poco desacreditada, no sólo por el corto número de cursantes que â ella concurren, sino también por el ningún zelo y poca aplicazión de muchos de los maestros y cathedráticos en su enseñanza» ${ }^{44}$.

Si por una parte el decreto de la alternativa limitaba la concurrencia de los opositores a cátedras en los concursos-oposiciones y se oponía directamente a otras órdenes reales que ordenaban que en las provisiones de cátedras se atendiese a los méritos y capacidad de los pretendientes, en una clara muestra de desorientación de la política en materia educativa ${ }^{45}$, por la otra, se planteaba claramente una reforma global de la enseñanza universitaria salmantina.

A su vez, el Consejo se dirigirá a la Universidad pidiendo un informe al respecto, transmitiéndola, por tanto, el testigo; la reforma se había puesto en marcha. La primera iniciativa de reforma global del Estudio, que había partido de la capital del Reino, será también la última; no obstante, se había encendido la mecha y será la propia institución universitaria, a partir de este primer intento fallido, la que tome el relevo de la reforma.

Las realizaciones reformadoras de la Universidad tuvieron como precedente la reforma de la enseñanza de la gramática latina, ordenada en el año 1703. Fueron despedidos dos de los tres catedráticos de Gramática (claustro pleno de $21-\mathrm{VII}-1703^{46}$ ) y se elaboraron una seria de medidas de reforma para estos estudios que fueron aprobadas en sesión plenaria de $29-\mathrm{VIII}-1703^{47}$. La reforma, con la que se pretendía aumentar el número de oyentes en estos estudios y mejorar su preparación, comprendía la

44 Libros de Claustros, A.U.S. 185, fs. 34, 34v.

45 Una real provisión posterior (Madrid, 11-III-1722) permitia la oposición de dos miembros de una misma comunidad religiosa a las cátedras de Filosofía y Teología de la Universidad de Salamanca, con tal de que se presentasen por escuelas distintas. Se atemperaba, de esta forma, el decreto de la alternativa dando cabida a mayor número de opositores. Fue obedecida la real provisión en claustro de rector y consiliarios de 21-IIl-1722. Libros de Claustros, A.U.S. 189, is. 30-31v. Recogida por Esperabe Arteaga, E., Historia pragmática..., op. cit., tomo primero, documento CIX, págs. 883-884. En cambio, no fructificó en la salmantina la pretensión del general de la Orden de San Francisco, fray Juan Bermejo, de que se decretase la alternativa de las escuelas tomista, jesuítica y escotista en las cátedras de Filosofía y Teología de las principales universidades, anunciada a la Universidad por real provisión de 22-Xl-1737, en Madrid. Libros de Claustros, A.U.S. 205, fs. 4v-6v. La idea de la tripartita fue rechazada por el Estudio salmantino, Vid. ibidem, A.U.S. 205, fs. $4 v-6 v, 7,9,9 v, 11,11 v$.

${ }_{46}$ Libros de claustros, A.U.S. 171 , fs. $35-36 \mathrm{v}$

47 Ibidem, A.U.S. 171 , fs. $46 \mathrm{v}-51 \mathrm{v}$. Se había encargado su elaboración al padre maestro Ignacio Camargo, teólogo, y al maestro don Martín Cubilano, graduado en Artes y catedrático de Prima de Humanidad, quienes las expusieron al claustro en forma de memorial. ldem, fs. $46 v-50 v$. 
enseñanza práctica de la doctrina cristiana y un completo programa para los maestros que impartían las clases de latín, insistiéndose metodológicamente en la memorización y la práctica, y en el control disciplinario y formativo. Se especificaban además los medios de ejecución de la reforma, que englobaban los aumentos salariales a los catedráticos, visitas generales y ordinarias, y la no permisión de otros estudios de Gramática en la ciudad ${ }^{48}$.

La reforma no tuvo los resultados apetecidos: los docentes impartían mal las clases y los alumnos continuaban siendo escasos y seguían estando mal preparados ${ }^{49}$. En el curso $1757 / 58$, en un intento desesperado por atraer alumnado, se despedía al preceptor de primera clase, por considerarse su método inadecuado, y se repartía temporalmente la docencia de Gramática entre los dos catedráticos restantes ${ }^{50}$.

Al final, la reforma de los estudios de Gramática se reducía a contratar un profesorado de buen carácter, que conectase con los niños, lo que demuestra hasta qué punto los claustrales estaban separados de la realidad del problema. En el hundimiento de la matrícula de los estudios de Gramática en la salmantina, que no es coyuntural, incidirían tanto las propias carencias y los problemas estructurales del Estudio de la ciudad del Tormes, como la desconsideración progresiva de la lengua latina como vehículo de expresión en los recintos universitarios españoles ${ }^{51}$.

La actitud reformista del Estudio salmantino se concretará en dos informes, aprobados en los años 1719 (claustro pleno de $30-\mathrm{VI}^{52}$ ) y 1736 (claustro pleno de $15-\mathrm{VI}^{53}$ ), bajo circunstancias diferentes: el primero respondía a un requerimiento del Consejo Real, el segundo era remitido al mismo organismo por iniciativa de la Universidad. Ambos proyectos deben considerarse complementarios; de hecho, asi lo entendia la Universidad

Cf. Ibidem: A.U.S. 170 , fs. $57,57 v$; A.U.S. 171 , is. $35-36 v, 42,46 v-53 v$.

49 Testimonios al respecto, Ibidem: A.U.S. 176 , fs. 46 bis v- $47 \mathrm{v}$; A.U.S. 190 , fol. 43

50 Acuerdos de los claustros plenos de 30-VI y 23-IX de 1758. Cr. ibidem: A.U.S. 224, is $68,68 v, 71,71 v, 75 v-77$; A.U.S. 225, fs. $74 v-76,86 v-88,(88 v), 101 v, 102,105-108 v, 110-111$.

${ }_{51}$ Buena prueba de ello es la real orden de Fernando VI (Buen Retiro, 11-IX-1753), dírigida a las universidades, colegios, academias y conferencias particulares del reino, con el objeto de que tomasen las providencias más eficaces para el restablecimiento del latín en las funciones y disputas literarias, y ejercicios de oposición a las cátedras. La orden se hace saber a la Universidad por carta orden fechada en Madrid, a 17 de octubre de 1753. Ibidem, A.U.S. 220 , fs. $64 \mathrm{v}-65 \mathrm{v}$.

${ }_{52}$ Ibidem, A.U.S. 186, ts. 16-19v.

${ }_{53}$ El plan fue presentado y aprobado en claustro pleno de 15 de junio de 1736 con los votos necesarios para declararse, en virtud de la bula de Paulo III, nuevo estatuto. La Universidad mandó que se imprimiera y se entregase un traslado a cada catedrático para que lo explicasen a sus oyentes. Ibidem, A.U.S. 203, fs. 53v-55v. Acudieron a la reunión 31 claustrales. 
al pedir la tramitación del primer expediente. Temáticamente se conjuntaban, por cuanto el más temprano respondía al interés de los docentes y el más tardio al de los estudiantes. Habian transcurrido los años suficientes como para que los graduados pudieran aprehender las limitaciones de la primera reforma frustrada; en este sentido, el proyecto de 1736 perfeccionaría aquel primero. Ambos tienen en común el deseo de remediar la falta de estudiantes y de restituir a la Universidad a su antiguo esplendor.

El informe de $1719^{54}$, con adiciones aclaratorias del año $1726^{55}, \mathrm{com}$ binaba la tradición con la novedad. Reconoce los aspectos demográficos de la crisis universitaria; profundiza en soluciones de corte tradicional o conservador, como la confirmación de los privilegios del Estudio, la observancia de la vieja normativa universitaria, el rigor académico y la supresión de las universidades menores (competidoras en la absorción del estudiantado); y revisa la docencia en las distintas facultades, planteando una serie de modificaciones, entre las que cabe destacar, por su nueva orientación, la modernización de ciertas enseñanzas (introducción del derecho patrio en las aulas, potenciación de las disecciones anatómicas, promoción del conocimiento práctico y divulgador de las hierbas en español) buscando despertar la curiosidad del alumno.

${ }^{54}$ Fueron designados por el claustro como comisarios para su elaboración los graduados más antiguos de cada facultad: por la de Derechos, los doctores don Bernardino Francos, don Joseph de Argüelles, don Manuel Martínez Carvajal y don Bernardo Santos; por Teología, los padres maestros fray Andrés Cid, Manuel Generelo, fray Pedro Manso y fray Mathías Terán; por Medicina, los doctores don Pedro Carrasco, don Pablo Gómez, don Pedro de San Martín y don Pedro de Reina; y por Artes, los doctores y maestros fray García de Pardiñas, don Pedro de Samaniego, don Carlos Elizondo y don Justo Morán. Ibidem, A.U.S. 186, fs. 10-12. Los comisarios encargaron, a su vez, el informe al doctor don Bernardino Francos. Una vez redactado el borrador, se reunirian los comisarios repetidamente para examinarlo. Confeccionado el informe, fue presentado en claustro pleno de 30 de junio de 1719 para su aprobación.

El memorial ocupó 18 hojas de papel común en letra menuda. En un primer momento se cosió al final del libro de claustros del curso 1718/19 (A.U.S. 186). Con posterioridad, fue descosido para su impresión, reemplazando finalmente al original manuscrito, que fue entregado al doctor Francos. El impreso consta de 32 páginas y está firmado por el rector y un representante de cada facultad, da fe el secretario.

${ }_{55}$ Demandadas por el mismo Consejo a instancia de la Junta de Ministros encargada de estudiar el informe de 1719 , a propósito, entre otras cosas, de la dotación de la cátedra de Simples de Medicina y la designación de un herbolario experto que ayude al catedrático en sus enseñanzas. Se encargó finalmente la respuesta al doctor jurista don Mathías Chafreón y fue leída en claustro pleno de 30 de abril de 1726 . El informe se recoge en el acta de la sesión. Ibidem, A.U.S. 193, ts. 39-45.

Por unanimidad los claustrales acordaron remitir al Consejo Real dicho informe, tal como fue leído, con la firma del vicerrector y el graduado más antiguo de cada facultad. Ibidem, A.U.S. 193 , fs. $38-47$. 
El informe de $1736^{56}$, completado con un memorial al Rey solicitándose un visitador (aprobado el mismo año, en claustro pleno de 3 de julio ${ }^{57}$ ), se proponía hacer atractivos los títulos salmantinos y dificultar la incorporación de los cursos y grados obtenidos en una universidad menor, sin las garantias suficientes. Para atraer la atención del estudiante se proponía un nuevo diseño académico que facilitase la consecución de los grados en la salmantina, basado en el recorte de los cursos necesarios para conseguir el bachilleramiento y de los años establecidos para la licenciatura.

Las mismas razones demográficas, el descenso de la población estudiantil, podían comprometer seriamente el funcionamiento del gobierno universitario. El encorsetamiento legal, el descenso de matrícula universitaria, cierto rechazo a ejercer los oficios y la desvalorización de los cargos hacían problemática la elección de rector y consiliarios.

El nuevo reglamento para la elección de los cargos de representación estudiantil ${ }^{58}$, aprobado en claustro pleno de $22-X \mid 1-1727^{59}$, estaba pensado para hacer flexibles estos nombramientos. El proyecto de reforma

56 En claustro pleno de 10 de diciembre de 1734 se acordó nombrar ocho comisarios, dos de cada facultad, para que reconocieran el memorial impreso del año 1719 y estudiasen los medios conducentes para atraer más estudiantes. Fueron nombrados como comisarios los doctores don Bernardino Francos y don Joseph Flores, juristas; los maestros padre fray Joseph Barrio y don Pedro Velarde, teólogos; doctores don Manuel Joly y don Pedro San Martín, médicos; y maestros don Manuel Peralbo y don Diego de Torres, artistas. Ibidem, A.U.S. 202 , fs. 7-9. El 29-IV-1735 se designó también como comisario de la junta al padre maestro Miguel de Sagardoy, teólogo. Ibidem, A.U.S. 202, fol 25.

Los puntos determinados por la junta de comisarios se encuentran en el acta de la sesión de claustro pleno de 15 de junio de 1736, en la que fueron leídos y debatidos. Vid. ibidem, A.U.S. 203, ts. $53 v-55 v$.

57 Destacó el dictamen del doctor don Joseph Flores, jurista, leido en claustro pleno de 29 de abril de 1735, quien pidió que se solicitase al Rey un visitador para la reforma del Estudio. Ibidem, A.U.S. 203, fs. 23, 23v. La propuesta fue aprobada por los vocales reunidos en claustro pleno de 22 de marzo de 1736, encomendándose la redacción del memorial a varios graduados: los doctores juristas don Bernardino Francos, don Alfonso de Quirós, don Joseph Flores y don Juan de Miranda. Ibidem, A.U.S. 203, fol. 23v. Éstos, a su vez, confiaron su redacción, siguiendo unas directrices determinadas, al doctor Miranda. Ibidem, A.U.S. 203, is, 24-25. Finalmente, en claustro pleno de 3 de julio de 1736 se aprueba por unanimidad el memorial que se remitirá al Rey, solicitando un "ministro visitador", con amplias facultades, para la reforma del gobierno político y económico del Estudio. El memorial en ibidem, A.U.S. 203, fs. 56-57; el acta de la sesión, en fols. 55v-57, ver también el tol. $57 \mathrm{v}$.

${ }_{58}$ Se encomendó su redacción a los doctores don Mathias Chafreón y don Simón de Baños, juristas, y los maestros padres fray Mathías Terán y Miguel de Sagardoy, teólogos. Ibidem, A.U.S. 194, fs. $111 \mathrm{v}-115 \mathrm{v}$. Tras diversas juntas, los comisarios presentan en claustro pleno de 22 de diciembre del año 1727 un reglamento para la elección de rector y consiliarios. Puede consultarse en el acta de la sesión. Ibidem, A.U.S. 195, fs. 20-27v.

59 La Universidad acordó aprobar el reglamento con más de las dos terceras partes de los votos (37 vocales), Ibidem, A.U.S. 195, fs. 18-29v. Ver también fs. $40 v-48$. 
universitario era conservador en sustancia, pero actualizaba la vieja normativa tomando como punto de referencia la problemática diaria. Se especifican los pasos a seguir en la elección del rector y consiliarios, dándose regla a todos los conflictos y situaciones que pudiesen presentarse a partir, básicamente, de la normativa vigente. Los apartados realmente originales están ideados para facilitar las elecciones a los cargos y para que los electos aceptasen los nombramientos sin poner reparos: se hacen más cómodos los requisitos para las elecciones, se suprimen aquellos factores que pudieran influir en la negativa de los estudiantes (se suprimen los gastos derivados de la elección y posesión de los cargos), a la vez que se buscan incentivos para hacer más atractivos los empleos (se concede al que hubiese desempeñado el oficio de rector el grado de bachiller). Las razones demográficas impulsan una nueva dimensión de la reforma universitaria que responde a razones prácticas: asegurar el relevo del representante honorífico de la Universidad y de sus consejeros.

La reforma no cristalizó. El expediente de 1719 quedó archivado en Madrid, mientras que el Consejo ordenaba la remisión de las disposiciones de 1727 y 1736, que la Universidad reconoció como nuevas leyes y estatutos ${ }^{60}$, a la vez que mandaba a la institución observar la vieja normativa hasta nueva orden ${ }^{61}$. El enfrentamiento jurisdiccional surgido entre el Consejo Real y la institución universitaria, sobre la asunción de la dirección del Estudio salmantino, y la presión de los colegiales mayores para hacer fracasar la reforma, por cuestiones honoríficas (reforma del año 1727) o prácticas (reforma del año 1736), resultaron impedimentos insuperables ${ }^{62}$.

60 En virtud de la bula del pontífice Paulo III. La bula fue dada en Roma, el 26 de octubre de 1543, y concedía a la Universidad salmantina autoridad apostólica para alterar, mudar o derogar sus constituciones y estatutos, y hacer otros nuevos, con la aprobación de las dos terceras partes del claustro. Se publica en la Recopilación de Estatutos (1625), págs. 125-128.

61 Con relación a la reforma de las elecciones de rector y consiliarios, hasta tanto llegaba el momento oportuno de transformar radicalmente la naturaleza de los cargos, y mientras el claustro universitario enmudecía, el Consejo recobraría la iniciativa años más tarde emitiendo decretos no comprometedores tendentes a impedir los excesos más llamativos relacionados con las elecciones. Una carta del Consejo de Castilla dirigida al maestrescuela de la Universidad salmantina, expedida en Madrid, el 1 de noviembre de 1749, salía al paso del desorden y abuso en los gastos que se producian con motivo de los nombramientos del rector y consiliarios, reduciéndolos considerablemente. Carta acordada leída y obedecida en claustro de vicerrector y consiliarios de 7 de noviembre de 1749. Libros de Claustros, A.U.S. 216, fs. 89v-90v.

La orden, que llegaba con retraso, recogía parte de los recortes económicos aprobados por el Estudio en su reglamento, aquellos que no dieron lugar a competencias honoríficas entre instituciones. Su efectividad fue limitada.

${ }_{62}$ Francisco Pérez Bayer se hace eco de los litigios de 1727 y 1736 en su memorial, achacando a los colegiales mayores la responsabilidad del fracaso de la reforma universitaria: respecto al episodio del año 1727, es de la opinión de que los colegiales, en unión con los consejeros, impidieron la reforma pretendida por la institución universitaria porque entendieron que se les obligaba a jurar, al tiempo de matricularse, el guardar las preeminencias al rector de la 
Tan sólo la Universidad pudo vertebrar un movimiento centrípeto de absorción de las academias particulares establecidas en los colegios y casas de la ciudad, que restaban, en un goteo continuo, cursantes y graduados a los ejercicios literarios (lecciones de extraordinario, actos de conclusiones) del Estudio.

Interesaba a los bachilleres acudir a tales academias; en ellas realizaban sus ejercicios de disputas para ejercitarse de cara a futuras oposiciones a plazas y prebendas, y los ejercicios que en ellas practicaban tenían reconocimiento académico. La Universidad reaccionó para contrarrestar este movimiento centrífugo, patrocinando sus propias academias; el objetivo de los claustrales era que estas juntas dependieran académicamente del Estudio salmantino.

Con ocasión de la súplica de once bachilleres juristas, que solicitaban el establecimiento en la Universidad de una academia de Derechos, los claustrales, reunidos el 1-XII-1749, concedieron a los profesores la erección de la academia pública, encargando a unos cuantos graduados la reglamentación de su puesta en marcha y un plan de actuación para que las academias privadas salmantinas se asentasen en el recinto universitario y bajo la dirección claustral ${ }^{63}$. En los cinco años siguientes se fundarian las academias de Teología y Medicina ${ }^{64}$, tomándose como modelo

\footnotetext{
Universidad; y que la prohibición de dar loables y conclusiones de seda en sus actos significaba una injerencia en su gobierno interno. Respecto al del año 1736, explica que los colegiales mayores, en complicidad con los excolegiales del Consejo, impidieron la reforma por el interés que tenian en que persistiesen las incorporaciones de bachiller $\sin$ los requisitos debidos: los colegiales mayores necesitaban un título improvisado y rápido para ser admitidos en los colegios; los consejeros excolegiales tenian interés en que sus hijos y parientes entrasen pronto en dichos centros. Vid., idem, Por la libertad de la literatura española. Estudio preliminar de MESTRE Sanchis, A., transcripción de $M{ }^{\text {a }}{ }^{\text {del }} \mathrm{C}$. Irles Vicente. Alicante 1991. Parte II, división I, §§. V y VII, págs. 290-298, 304-305, 308-310, 322-326. Las explicaciones me parecen razonables y encajan bien en el desarrollo de los acontecimientos.

63 Libros de Claustros, A.U.S. 216, is. 109v-111. Se nombraron como comisarios a los doctores don Jerónimo de Ruedas, don Francisco Agudo, don Diego Enterría y don Pedro Villegas, por la facultad de Derechos; padres maestros fray Francisco Sotelo y fray Juan Ladrón de Guevara, por Teología; y doctor don Francisco Vélez, por Medicina. Más tarde, en sustitución del doctor Villegas y maestro Guevara, ausentes por promoción, serían designados el doctor don Felipe Santos Dominguez (jurista) y el padre maestro Santiago García (teólogo). Acuerdo de claustro pleno de 19-Xl-1754. Ibidem, A.U.S. 222, fol. 4. Los capítulos de arreglo y disposición de la academia de Derechos fueron llevados a claustro pleno de 22 de diciembre de 1749 para su aprobación. Fueron copiados en el acta de la sesión. Ibidem, A.U.S. 217, fs. 3v-6. Se incluyen, igualmente, en los Estatutos manuscritos de la Universidad de Salamanca, A.U.S. 2.885 , fs. $13 \mathrm{v}-22 \mathrm{v}$ del último cuadernillo. Los arreglos y condiciones fueron aprobados sin dificultad. lbidem, A.U.S. 217 , fs. 3-8.

${ }_{64}$ El reglamento de la Academia de Medicina se encuentra en Reglamentación y planes de estudios de la Universidad de Salamanca y sus facultades. Reales provisiones, cédulas y órdenes de reforma de enseñanza. A.U.S. 2.032, sección 17,4 folios.
} 
las academias de jurisprudencia. En este tiempo y en los años siguientes la junta de comisarios resolvería sobre la marcha los problemas suscitados con la erección y puesta en funcionamiento de las academias de las facultades mayores, modificando y ampliando las primeras constituciones elaboradas para cada una de ellas, y decretaría sobre los recursos planteados que tuviesen relación con el proceder de los integrantes de las mismas (actuaban como «jueces de academias"); el claustro pleno se limitaba a dar carácter oficial a sus decisiones, a proveer las moderaciones vacantes y a emitir las resoluciones definitivas por causa de apelación. Las directrices seguidas por la junta y el claustro consistieron en potenciar la figura del moderante, como interlocutor y nexo de unión entre los comisarios de academias y académicos; y en impulsar estas organizaciones controladas por la institución frente a otras independientes ${ }^{65}$.

$\mathrm{Ni}$ el Rey ni el Consejo ni la Universidad abordaron, en el debate de las reformas, los aspectos estructurales de la crisis: los desequilibrios en la representación y participación de los distintos colectivos que conforman el cuerpo universitario, en los sucesivos tramos académicos. Existe la conciencia de crisis del primer Estudio de España, medida en todo instante por la escasa presencia de oyentes en las aulas, pero se buscan soluciones académicas desde razonamientos superficiales, con originalidad en determinadas facetas y de forma tradicional y conservadora en otras, a un problema que era estructural, esencialmente socioacadémico. Las disposiciones en este terreno siempre fueron tangenciales, se orientaron más hacia afuera, evitar la competencia universitaria, por ejemplo, que hacia dentro, lograr la justicia distributiva en la provisión de cátedras y empleos, lograr, en definitiva, la igualdad académica; tales circunstancias restarían efectividad a los proyectos reformistas planteados, que al fin no tuvieron su plasmación.

Entiendo que la solución a la crisis de despoblación que experimentaba la Universidad salmantina del siglo XVIII pasaba por la superación de la contradicción estructural de los grupos socioacadémicos que la componían, por una nueva redistribución de sus efectivos. Hemos observado que desde el inicio de la trayectoria académica del universitario, los colegiales mayores, sobre todo ellos, y los religiosos, consolidan progresivamente su presencia numérica proporcional en detrimento de los estu-

65 Acuerdos de la junta de comisarios de academias, de claustros plenos y otros; órdenes del Consejo Real; y memoriales generados por los miembros de las academias en Libros de Claustros: A.U.S. 222, fs. 3-4, 16v-18v, 29-34, 48v-51v, 54v-55v, 79-80v; A.U.S. 224, fs. 31-33; A.U.S. 225 , fs. $34 v, 56-57 v$; A.U.S. 226 , fs. $3-4,9 v-10 v, 20 v-24,37 v-38 v, 46 v-47 v, 54 v-55 v, 86 v$, 87. 
diantes manteístas. Estos desequilibrios se nutren precisamente del abandono de la Universidad del estudiante ordinario que antes frecuentara masivamente las aulas de Derecho y que ahora renuncia a la carrera universitaria ante las escasas perspectivas de futuro en el horizonte. El desigual reparto de los premios literarios y las escasas expectativas de trabajo, altamente cualificado, para un amplio espectro de la población universitaria, constituyen las deficiencias subyacentes que serán, al fin y al cabo, las que desencadenen el proceso que conducirá a la situación de crisis. Cualquier medida que pretendiera elevar la matrícula del Estudio, hubiera debido enfrentarse ineludiblemente a este problema. La superación de esta dialéctica interna se producirá a la vuelta de siglo, por puro agotamiento de las estructuras vigentes, en una nueva época, en la que las capas dirigentes del Estado tenian un tejido social diferente y se suministraban de otras universidades remozadas, distintas a las privilegiadas por el Antiguo Régimen universitario. Era el fin de un período del que la Universidad de Salamanca era hija y máximo exponente; junto con el Antiguo Régimen, en letras grandes, desaparecerá un modelo de Universidad.

\section{PROYECTO DE FUNDACIÓN DE LA ACADEMIA DE MATEMÁTICAS}

Por último, ideas de reforma podian provenir de iniciativas individuales que deseaban un cambio en la enseñanza por si mismo; de personas inconformistas con pensamientos que no se encasillaban en su tiempo.

En el año 1758 asistimos a un interesantísimo debate sobre la práctica docente de las Matemáticas protagonizado por los maestros Torres Villarroel y Bernardo de Ribera. Este breve episodio de la historia universitaria nos presenta dos concepciones distintas sobre lo que tienen que ser los estudios universitarios, una innovadora y otra tradicional, cuyo enfrentamiento va a caracterizar a un siglo universitario.

El claustro pleno congregado el 30-1-1758 había acogido favorablemente la iniciativa del maestro Torres Villarroel, catedrático jubilado de Matemáticas, apoyada por su sobrino, don Isidoro Ortiz Gallardo, actual regente de dicha cátedra, tendente a la erección de una academia, cátedra - estudio práctico, para enseñar el uso, utilización y fábrica de unas esferas terráquea y celeste que habia adquirido recientemente para la biblioteca universitaria ${ }^{66}$, así como de otros instrumentos matemáticos que

66 Se trata de una impresión, en París, de 1751 de unas esferas fabricadas por Robert Vaugondy, que recogía las observaciones de las expediciones científicas de su tiempo (se citan 
tenía previsto construir. A tal fin, se autorizaba la traducción e impresión del tratado escrito francés sobre el manejo de los globos dichos de su mismo autor, Robert Vaugondy, al idioma latín o castellano, que había propuesto Torres como manual para los futuros alumnos ${ }^{67}$.

Al margen de las limitaciones evidentes en el conocimiento de las Matemáticas de Torres; al margen de las intenciones pecuniarias que escondía el proyecto de academia ${ }^{68}$, indudables, y considerando que podía anidar también en los catedráticos de Matemáticas una sincera preocupación por la enseñanza de esta disciplina (ambas motivaciones no son excluyentes), lo cierto es que la iniciativa de unas lecciones prácticas y de carácter divulgador, al margen del academicismo imperante en las aulas universitarias ${ }^{69}$, traía aparejada una novedosa concepción de la docencia de las Matemáticas, que es lo que nos interesa, y por tanto, significaba una importante contribución a la reforma de la enseñanza universitaria. Por otra parte, la traducción realizada reflejaba un interés también desconocido por el uso de libros modernos y en castellano.

El maestro Diego Torres Villarroel ${ }^{70}$, catedrático jubilado de Matemáticas, pensaba, como su sobrino, en una enseñanza abierta de esta disciplina, dirigida a estudiantes, profesionales y aficionados, y exclusivamente práctica, para atender las demandas de unos oyentes que asistían al aula por vocación:

los nombres de La Condamine, Antonio de Ulloa, Jorge Juan, y los viajes misioneros de la Compañia de Jesús). Los globos llegaron a Salamanca el 10-1-1758, presentándolos Torres Villarroel a los comisarios de la librería el 20 del mismo mes y año. Ibidem, A.U.S. 225, fs. 13v$15 \mathrm{v}$.

67 Ibidem, A.U.S. 225, fs. 13-16. La intervención de Torres, dada por escrito, en los fs. $13 \mathrm{v}$ $15 v$.

6 Los hermanos PESET, M. y J.L., en su trabajo "Un buen negocio de Torres Villarroel», Guadernos hispanoamericanos, núm. 279 (Madrid 1973), págs. 514-536, analizan el interés económico que ocultaba la propuesta de Torres Villarroel y su sobrino.

69 El estatuto repartía las lecturas del catedrático de Matemáticas y Astrologia en un ciclo de cuatro años: la aritmética y geometría se leerian siguiendo a Euclides; la astronomía, a partir de las obras de Ptolomeo y sus comentadores, teniendo cabida las tablas astronómicas de Nicolás Copérnico. También se impartían nociones de agrimensura, gnomónica, geografía, cartografía, arte de navegar y militar. Vid. Recopilación de Estatutos (1625), título XVIII.

70 En opinión de CuESTA DUTARi, N., el maestro Torres ignoraba las Matemáticas europeas de su tiempo. Desconocía el Análisis Infinitesimal y la Mecánica Analítica, contentándose con tener vagas noticias de las Matemáticas que se enseñaban en las academias militares españolas y un superficial conocimiento de la Cosmografía; y con seguir las obras de Ptolomeo y Sacro Bosco, y publicar pintorescos Almanaques. Considera el mismo autor que el proyecto de Academia propuesto por Torres y Ortiz se reducía a "unas modestas lecciones prácticas". Vid. Idem, El maestro Juan Justo García, Presbitero natural de Zafra, 1752-1830, segundo catedrático de álgebra de la Universidad de Salamanca desde 1774 y creador del Colegio de Filosofia en 1792. Salamanca 1974 (2 vols.); vol. I, págs. 45-71. Ver también del mismo, Las matemáticas en Europa y en España en tiempos de Torres Villarroel. Salamanca 1984, págs. 1-8, 30-39. 
«El mecanisco [sic] de la Mathemática contiene muchos tratados, tan distantes entre sí, que se pueden aprehender y practicar lo vnos sin el más leve conocimiento de los otros. Los discípulos que en nuestro tiempo han venido y pueden venir por haora, son regularmente vnos afizionados altaneros, de diferentte y extrabagante genio, sin sugezión alguna a las leyes de la enseñanza, sin miedo al castigo, sin esperanza al premio y, finalmente, libres de susto de haverse de presenttar en los theatros adonde exponen su reputación los profesores de la Sagrada Theologia, Jurisprudencia y otras ciencias, que tienen formalidad en la educazión y premio en los fines y medios de ella. Suelen venir a cada curso quatro ô seis de estos sugetos â aprender Mathemática, y preguntados por el maestro, vno dize que quiere aprender Geometría, otro que Nogmónica y otro que la Architectura... me acomodé al genio y al deseo de los discípulos que venían, de modo que en la hora de la cáthedra a vnos daba lección de Geometría, a otros de esphera y a otros de la facultad mathemática a que se inclinaban, reforzándolos después con las conversaciones y conferencias en los patios ô en mi casa; y de este modo pude instruir a los discípulos que hoy hacen vanidad en el reyno de haverlo sido mios " ${ }^{71}$.

Sorprendentemente, unos meses después la Universidad decía no al proyecto de fundación de la academia de Matemáticas. La mayoría de los claustrales reunidos en sesión plenaria de 11-V-1758 para estudiar las instrucciones sobre los ejercicios de la academia que una junta de comisarios había preparado, acordaron paralizar el asunto de la fundación y mandaron retirar y depositar en secretaría todos los ejemplares de la traducción ${ }^{72}$.

Entre las razones de la negativa debemos destacar los mal disfrazados intereses económicos de los catedráticos, mal vistos por los miembros del claustro; la envidia y rencor que desprendía la figura afamada de Torres, y sobre todo, la tenaz oposición al proyecto del padre maestro fray Manuel Bernardo de Ribera, secundado por el doctor don Francisco Ovando, médico, integrantes de la junta de fundación de la academia.

El maestro fray Manuel Bernardo de Ribera ${ }^{73}$, catedrático de San Anselmo, pertenecía al colegio de graduados más conservador de la Uni-

${ }^{71}$ Papel de don Diego de Torres firmado en Salamanca, a 25 de abril de 1758, y leído en claustro pleno de 11 de mayo del mismo año. Libros de Claustros, A.U.S. 225, fs. 44-45. La cita corresponde a los fs. $44,44 \mathrm{~V}$.

72 lbidem, A.U.S. 225, fs. 35, 35v, 41-54.

73 George M. Addy dedica unas páginas a esta figura intelectual en su trabajo, The Enlightenment..., Op. cit., págs. 75-84. SIMON REY, D., nos informa de la vida y escritos de este catedrático en las págs. 300-306 de su obra, Las facultades de Artes y Teología en la Universidad de Salamanca en el siglo XVIII. Salamanca 1981. En su opinión, la característica más sobresaliente del pensamiento de este docente es "su concepto del verdadero progreso de las ciencias y su fe en la posibilidad de armonizar lo moderno y lo antiguo, conservando lo uno y lo otro." Ibidem, pág. 303. 
versidad salmantina en lo referente a las reformas de estudios. Consideraba las ciencias Matemáticas, de las que tenia nociones generales, y en especial la Geometría, necesarias en la formación del teólogo, particularmente de aquél que en calidad de maestro se adentre en la Dialéctica y Filosofía para explicar la Teología.

Era de la opinión de que las asignaciones del estatuto eran suficientes para impartir esta disciplina, y por tanto, resultaba innecesario el establecimiento de una academia específica para su enseñanza:

«...si por haora no se descubre motivo para fundar segunda cáthedra de Mathemáticas, tampoco le hai para establezer dicha academia. Dixe que el cathedrático de Mathemáticas, sólo con desempeñar los deberes que prescribe el estatuto, hará vn servizio al rey i a la patria" ${ }^{74}$

Respecto a la traducción del libro de Robert de Vaugondy, encontraba muchos «lunares» que la hacían muy deficiente. Dejando al margen las faltas de puntuación y ortografía, eran numerosos los errores de traducción. Además, en el libro de los traductores hay partes del original que faltan y otras que son añadidas. Pero la tacha más importante que se le puede hacer es que está escrito en lengua vulgar y no en el académico latín ${ }^{75}$.

A partir del instante de la negativa universitaria se producirá la ruptura del diálogo entre los catedráticos de Matemáticas y la Universidad, y se iniciará un enfrentamiento entre ambas partes que será resuelto en Madrid $^{76}$.

El proyecto de una enseñanza práctica de Matemáticas, orientada a todo tipo de oyentes e impartida por medio de un manual en castellano,

74 Libro de Claustros, A.U.S. 225, fol. 50.

75 Papel firmado de su nombre leído en claustro pleno de 11-V-1758, que contiene los reparos manifestados en junta de comisarios sobre la fundación de la Academia de Matemáticas de 26-IV del mismo año. Ibidem, A.U.S. 225, is. 47v-53. La cita corresponde al fol. 50.

${ }^{76}$ La polémica del año 1758 en torno a la fundación de la academia de Matemáticas y la traducción del tratado de Robert Vaugondy puede seguirse en el Libro de Claustros correspondiente al curso $1757 / 58$ (A.U.S. 225), fs. 13-16, 28-31, 32v, 33, 35, 35v, 41-54v, 60-62v, 66v-71, $80 v-86 v, 92,92 v, 114,114 v, 124 v, 125$. Ver también el libro siguiente (A.U.S. 226), fs. 13-15. Un memorial impreso por la Universidad relativo a la fundación de la academia de Matemáticas, con otra documentación relacionada, se encuentra a disposición del lector en el legajo: Reglamentación y Planes de estudios de la Universidad de Salamanca y sus facultades. Reales provisiones, cédulas y órdenes de reforma de enseñanza. A.U.S. 2.032, sección 35, 37 páginas.

La academia se aprobaría en 1762, aunque parece ser que con escasos resultados. Una carta orden del Consejo Real fechada en Madrid, a 20 de julio de dicho año, notificaba a la Universidad la decisión, que fue acatada. Libros de Claustros, A.U.S. 229, fs. 19, 19v. 
no cuajó finalmente; la Universidad de Salamanca, deudora de un pasado glorioso, seguía aferrada a la tradición, haciendo inviable, por el momento, cualquier intento por introducir el estudio moderno en sus aulas.

Con esta apretada visión, hemos querido dejar constancia del deseo de reforma en los hombres que vivieron durante los reinados de los primeros Borbones, que otorga a la Universidad de Salamanca de los primeros sesenta años del siglo XVIII caracteres culturales propios. Bien es cierto que la reforma planteada era limitada, pluriforme, confusa y recogía tanto planteamientos tradicionales como novedosos; sin embargo, es en el reconocimiento uniforme de la crisis universitaria y en la variedad de concepciones sobre lo que tiene que ser la transformación de tal realidad, donde reside la originalidad del período abarcado. Este burbujear de inquietudes que experimenta la salmantina durante las seis primeras décadas del Setecientos, preparará el camino a los grandes cambios que han de llegar a la institución; tengamos presente que sólo desde la consideración del siglo xvIII en su conjunto, podremos comprender plenamente el fenómeno de la llustración en la Universidad española. 